\title{
A COLABORAÇÃO DO GÊNERO TEXTUAL HISTÓRIA EM QUADRINHOS NO DESENVOLVIMENTO DA LEITURA E ESCRITA
}

\author{
LA COLABORACIÓN DEL GÉNERO TEXTUAL HISTORIA EN CUADRINOS EN \\ EL DESARROLLO DE LA LECTURA Y ESCRITA
}

THE COLLABORATION OF THE TEXTUAL GENDER HISTORY IN QUADRINHOS IN THE DEVELOPMENT OF READING AND WRITING

\author{
Camila Holz KRÜGER ${ }^{1}$ \\ Josué MICHELS ${ }^{2}$
}

\begin{abstract}
RESUMO: O presente trabalho traz como tema o uso de histórias em quadrinhos nas atividades com alunos que apresentam alguma dificuldade na aprendizagem. Tivemos como objetivo a elucidação dos fatores presentes na produção dos quadrinhos e que contribuem com o processo de desenvolvimento da leitura e da escrita. O trabalho foi realizado com um grupo de quatro alunos de anos iniciais do ensino fundamental. Foram oito encontros, duas vezes na semana. A partir da construção das histórias obteve-se a análise de conteúdo de cada produção. Através dos quadrinhos os alunos desenvolveram uma narrativa gráfica, despertando os pressupostos da escrita de uma maneira mais dinâmica. Verificou-se a presença da escrita e do desenho integrados, fazendo com que a construção de uma história e sua comunicação ficasse mais fluente. O diálogo entre os personagens favoreceu a escrita na construção. Pode-se constatar que essas atividades valorizaram a capacidade de cada aluno, buscando o conhecimento através do processo de ensino-aprendizagem.
\end{abstract}

PALAVRAS-CHAVE: Histórias em quadrinhos. Escrita. Educar pela pesquisa.

RESUMEN: El presente trabajo trae como tema el uso de historietas en las actividades con alumnos que presentan alguna dificultad en el aprendizaje. Hemos tenido como objetivo la elucidación de los factores presentes en la producción de los cómics y que contribuyen con el proceso de desarrollo de la lectura y la escritura. El trabajo fue realizado con un grupo de cuatro alumnos de años iniciales de la enseñanza fundamental. Fueron ocho encuentros, dos veces a la semana. A partir de la construcción de las historias se obtuvo el análisis de contenido de cada producción. A través de los cómics los alumnos desarrollaron una narrativa gráfica, despertando los presupuestos de la escritura de una manera más dinámica. Se verificó la presencia de la escritura y del diseño integrados, haciendo que la construcción de una historia y su comunicación quedara más fluida. El diálogo entre los personajes favoreció la escritura en la construcción. Se puede

\footnotetext{
${ }^{1}$ Instituto Federal Sul-Riograndense (IFSUL), Pelotas - RS - Brasil. Especialista em Ensino de Ciências e Matemática: Educar pela Pesquisa. E-mail: camilahk19@gmail.com

${ }^{2}$ Universidade Luterana do Brasil (ULBRA). Doutorando em Ensino de Ciências. Professor do Ensino Básico e Tecnológico do Instituto Federal Sul Rio-Grandense IFSUL. ORCID: <http://orcid.org/0000-00022227-4411>. E-mail: jcmichelsbio@gmail.com
} 
constatar que esas actividades valoraron la capacidad de cada alumno, buscando el conocimiento a través del proceso de enseñanza aprendizaje.

PALABRAS CLAVE: Cómics. Escritura. Educar por la investigación.

ABSTRACT: The present work brings as a theme the use of comics in the activities with students who present some difficulty in learning. We had as objective the elucidation of the factors present in the production of comics and that contribute to the process of development of reading and writing. The study was carried out with a group of four students from the first years of elementary school. There were eight meetings, twice a week. From the construction of the histories the content analysis of each production was obtained. Through the comics the students developed a graphic narrative, awakening the assumptions of writing in a more dynamic way. It was verified the presence of integrated writing and drawing, making the construction of a story and its communication more fluent. The dialogue between the characters favored writing in the construction. It can be verified that these activities valued the capacity of each student, seeking the knowledge through the learning teaching process.

KEYWORDS: Comics. Writing. Educate by research.

\section{Introdução}

O maior desafio para os docentes que atendem alunos com dificuldades na aprendizagem é reconhecer a individualidade de cada um, de acordo com a sua essência. Partindo desta realidade em que todos os alunos são diferentes, tanto em suas capacidades, quanto em suas motivações, interesses, ritmos evolutivos, situações, ambientes, entre outras, devemos ter em mente que nem todos aprendem da mesma maneira, que cada uma aprende a seu ritmo e em seu nível.

O indivíduo enfrenta o processo de aprendizagem como uma totalidade, ou seja, a partir de seus sentimentos, seu corpo, sua capacidade intelectual e do seu esquema referencial. Quando surge dificuldades nesse processo, elas não devem ser enfocadas separadamente. Aprender é um processo complexo que apresenta bloqueios e inibições em todos os indivíduos.

Devido a uma quantidade de alunos com carência no desempenho de habilidades específicas e práticas diárias, a escola vem desenvolvendo um projeto para sanar essas dificuldades existentes nos alunos da instituição. Tornando-se necessário implementar novas propostas de intervenção ou de acompanhamento/avaliação do trabalho que está sendo realizado. 
Os quadrinhos como proposta didática estimulam os alunos a desenvolverem uma narrativa gráfica, despertando os pressupostos da escrita de uma maneira mais dinâmica. Através dos quadrinhos cria-se a interação de personagens, demostrando sentimentos e expressões corporais que desenvolvem a comunicação e expressão, elementos que são fundamentais para transmitir a ideia, a interpretação e a emoção.

Pergunta de pesquisa: A partir da presente proposta instituímos a seguinte pergunta de pesquisa: Quais as características das histórias em quadrinhos e como elas podem contribuir para o desenvolvimento da leitura e escrita dos alunos?

É difícil encontrar uma definição de aprendizagem, pois envolve uma série de fatores no processo do "aprender". O aprendizado está associado ao desenvolvimento cerebral, psíquico, cognitivo e social.

Atualmente "aprender" não é transmitir conhecimentos de forma receptora, onde os alunos apenas recebem informações. A aprendizagem é um processo constante de construção, em que o professor se torna um mediador e não um transmissor de saberes. A interação entre aluno e professor traz a troca de conhecimentos, estimulando o pensar, o questionar, e possibilitando uma aprendizagem de forma significativa.

O indivíduo necessita de contínuas aprendizagens que se iniciam a partir da gestação do ser humano. O "descobrir" é o caminho para atingir o conhecimento, o equilíbrio e o desenvolvimento como seres humanos em um ambiente em que haja interações com o meio para a realização do conhecimento.

A escola é uma instituição com diversas funções. Uma delas é proporcionar condições para que os alunos aprendam. Muito longe de ter um mapa único e definitivo, o caminho da aprendizagem está repleto de diferentes respostas para a mesma pergunta.

Segundo Farrell (2009, p.13), "Proporcionar os recursos necessários ao aluno com necessidades especiais permite que este tenha o melhor progresso acadêmico e que se desenvolva ao máximo em termos pessoais e sociais". Esse projeto busca desenvolver essa interação com o discente e o meio em que ele está inserido. $\mathrm{O}$ discente deve ser estimulado pelo docente e deve estar preparado para receber as informações, utilizando recursos e estratégias que auxiliem na sua compreensão.

Um dos múltiplos desafios a ser enfrentado pela escola é o de fazer com que os alunos aprendam a ler e escrever corretamente. De acordo com Solé: 
aproxime do mundo de seus significados de um autor e lhe oferece novas perspectivas ou opiniões sobre determinados aspectos...etc. (1998, p. 46).

Conforme Melchior (2008), cabe ao docente transformar a aula, valorizando o pensar do discente, seus interesses, estabelecendo relações de troca onde o conhecimento seja compartilhado em um processo coletivo de aprender. Faz com que se busque também desenvolver algumas competências e habilidades criando espaços para que o aluno produza diversas possibilidades para ampliar seus conhecimentos. Para que o processo de aprendizagem ocorra de maneira clara é importante salientar que aconteça motivações e hábitos de leitura e escrita.

A excessiva insatisfação com relação à escrita vem ocorrendo com indivíduos diretamente envolvidos no processo de ensino-aprendizagem. Os alunos mostram-se desacreditados em relação a sua própria competência escrita. Cabe ao professor incentiválos a tornar o processo do 'aprender a fazer"mais produtivo.

Trabalhar nesse processo de escrita exige do professor uma capacidade de ajudar seu aluno a utilizar e adaptar estratégias de criações textuais. Através da capacidade de cada um, é que se oportunizam condições para desenvolverem um trabalho que desperte o interesse dos alunos e tragam para a aula temas que instiguem o pensamento.

Com isso viu-se necessária a importância de desempenhar trabalhos utilizando os gêneros textuais como principal recurso para as atividades desenvolvidas.

A comunicação verbal só é possível por meio de algum gênero textual que se materializa em textos que assumem formas variadas. Os gêneros textuais são instrumentos culturais, onde ocorre a interação de cada um deles.

Fundamentam-se em meios sóciocomunicativos, onde cada gênero tem a função de relatar as várias intenções que cada indivíduo busca de acordo com o jeito de expressar-se.

Após a escolha de trabalhar com gêneros é importante que se realize uma organização das atividades. A partir de uma " sequência didática", ou seja, um conjunto de atividades que serão realizadas de forma mais sistemática, ajudando o aluno a dominar melhor o gênero e assim permitindo que reproduza na forma escrita ou falada a atividade proposta. É importante que ocorra essa ordem de ideias e a formação de seres pensantes, incorporando novas aprendizagens.

As histórias em quadrinhos fazem parte do nosso dia-a-dia. Esse interesse e o acesso que os alunos têm faz com que eles se sintam mais motivados e curiosos a desenvolver leituras e escritas em quadrinhos. Segundo Vergueiro e Rama (2004), "As 
histórias em quadrinhos aumentam a motivação dos estudantes para o conteúdo das aulas, aguçando a curiosidade e despertando seu senso crítico".

Através das histórias em quadrinhos ocorre grandes possibilidades de se desenvolver diferentes linguagens, como a gráfica, a oral e a escrita, despertando o uso de vários meios de comunicação, colaborando para um processo de aprendizagem mais interativo.

\section{Materiais e métodos}

O desenvolvimento do Projeto foi realizado em uma Escola Municipal do interior do Rio Grande do Sul, no período da tarde, no turno inverso das atividades curriculares do corrente ano letivo.

A instituição dispõe de uma sala específica com vários livros e recursos didáticos para melhor desempenho do grupo de alunos com dificuldades de aprendizado.

A realização das atividades teve a colaboração de um grupo de quatro alunos, divididos em oito encontros. Esses encontros foram realizados duas vezes por semana, totalizando um período de 32 horas.

Para que o processo de ensino-aprendizagem ocorresse de maneira mais eficiente, foram trabalhados passos de uma sequência didática. Planejamos as etapas do trabalho com os alunos, de modo a explorarmos diversas formas de aprender, utilizando diferentes linguagens com aplicação de diferentes tipos de gêneros textuais, ampliando a competência comunicativa com a escrita e a leitura e desenvolvendo habilidades, favorecendo uma aprendizagem significativa.

Essas rotinas de atividades foram ministradas em cinco momentos, objetivando o processo de compreensão e valorização da escrita e o desenvolvimento da oralidade. Para a execução das atividades em cada encontro, foi escolhido o tema gerador "alimentação", trabalhando com diversos gêneros textuais, como: diário, receita, propaganda, poesia e história em quadrinhos.

$\mathrm{Na}$ presente proposta destacamos o gênero textual " história em quadrinhos", no qual foram realizados dois encontros, um em cada semana. No começo das atividades foram apresentadas várias coleções e materiais sobre a alimentação, para que os alunos conhecessem melhor o tema a ser explorado. Todo o trabalho teve como base os pressupostos do educar pela pesquisa (DEMO, 2011). 
A proposta pedagógica do educar pela pesquisa fundamenta-se na inserção de algumas dimensões do ato de investigar nas atividades propostas em sala de aula. Questionamento, construção de argumentos, produção escrita, aproximação da realidade com os conteúdos escolares e diálogo são os princípios de pesquisa, incorporados na sala de aula investigada, sobre os quais o estudo foi aprofundado (LIMA, 2003).

Após a conversa aberta e exposição dos materiais sobre o tema, foram apresentados diversos gibis, para que eles percebessem a mistura do texto e do desenho de maneira única. Os alunos identificaram a existência das falas entre os personagens, onde deveriam ser colocados em forma de balões e também a utilização de onomatopeias, ou seja, palavras que expressam sons.

Os conhecimentos desses instrumentos para a construção das histórias em quadrinhos mostram a importância de reconhecer e desenvolver habilidades e competências no processo ensino-aprendizagem.

A partir daí, foram iniciadas as construções das histórias em quadrinhos. Cada aluno pode demostrar através do desenho e escrita suas ideias, para representá-las no papel. Essas produções envolveram a imaginação, a criatividade e o entendimento dos acontecimentos das histórias produzidas.

Em seguida cada aluno expôs suas produções para os demais colegas do grupo, desenvolvendo o diálogo e aprimorando a oralidade e desenvoltura de cada um. Como fechamento dessa atividade foram colocados todos os trabalhos no mural da sala, para que os demais alunos do projeto pudessem apreciar as produções.

A observação realizada ao longo das aulas e a produção das histórias em quadrinhos serviram como subsídios para análise de dados, realizada em acordo com a proposta e análise de conteúdo de Bardin (2011).

\section{Resultados e Discussões}

Segue abaixo a produção individual das histórias em quadrinhos de cada aluno.

Figura 1: História em quadrinhos produzida pelo aluno 1 


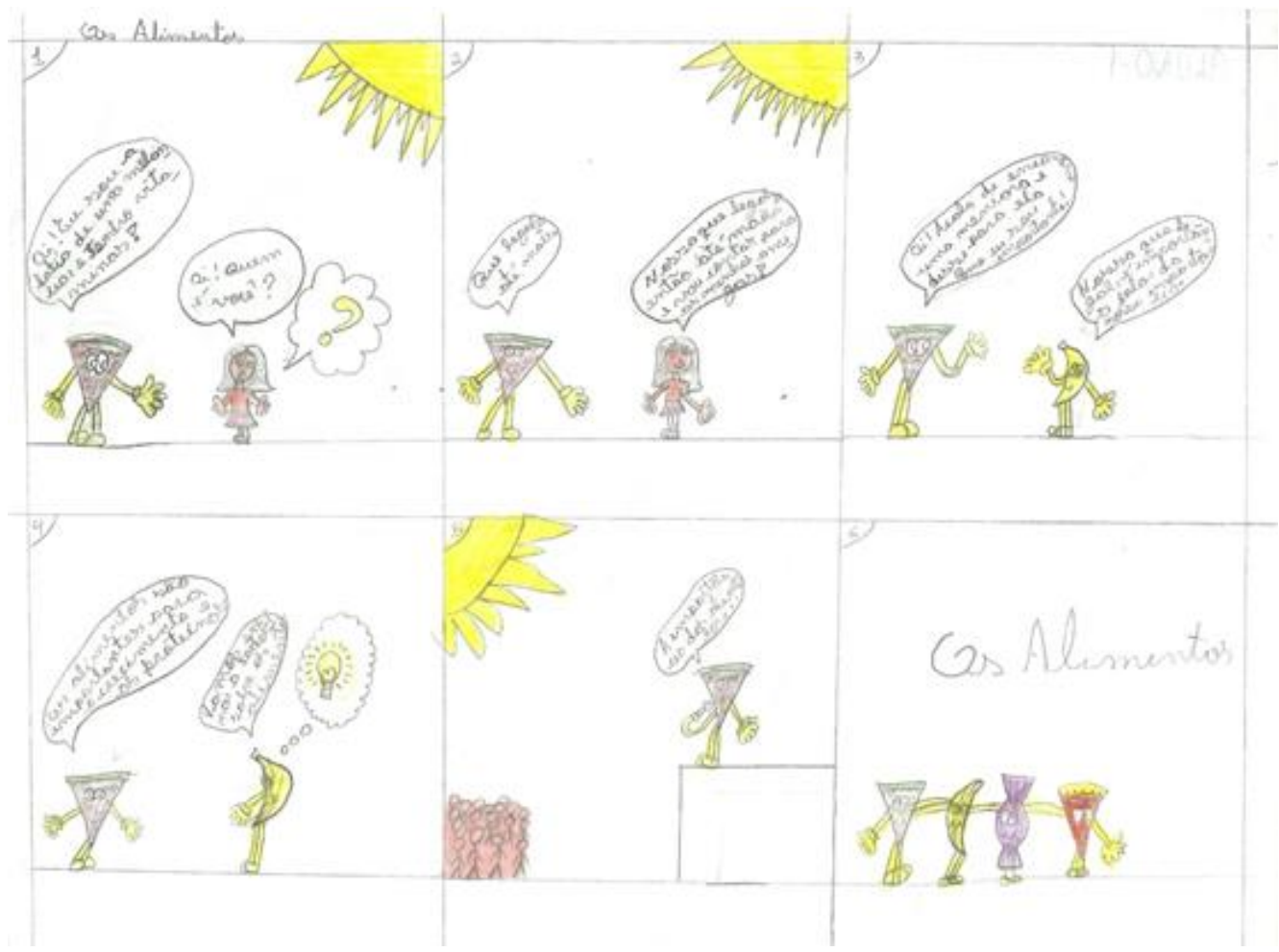

Fonte: elaborada pelos alunos desta amostragem.

Figura 2: História em quadrinhos produzida pelo aluno 2

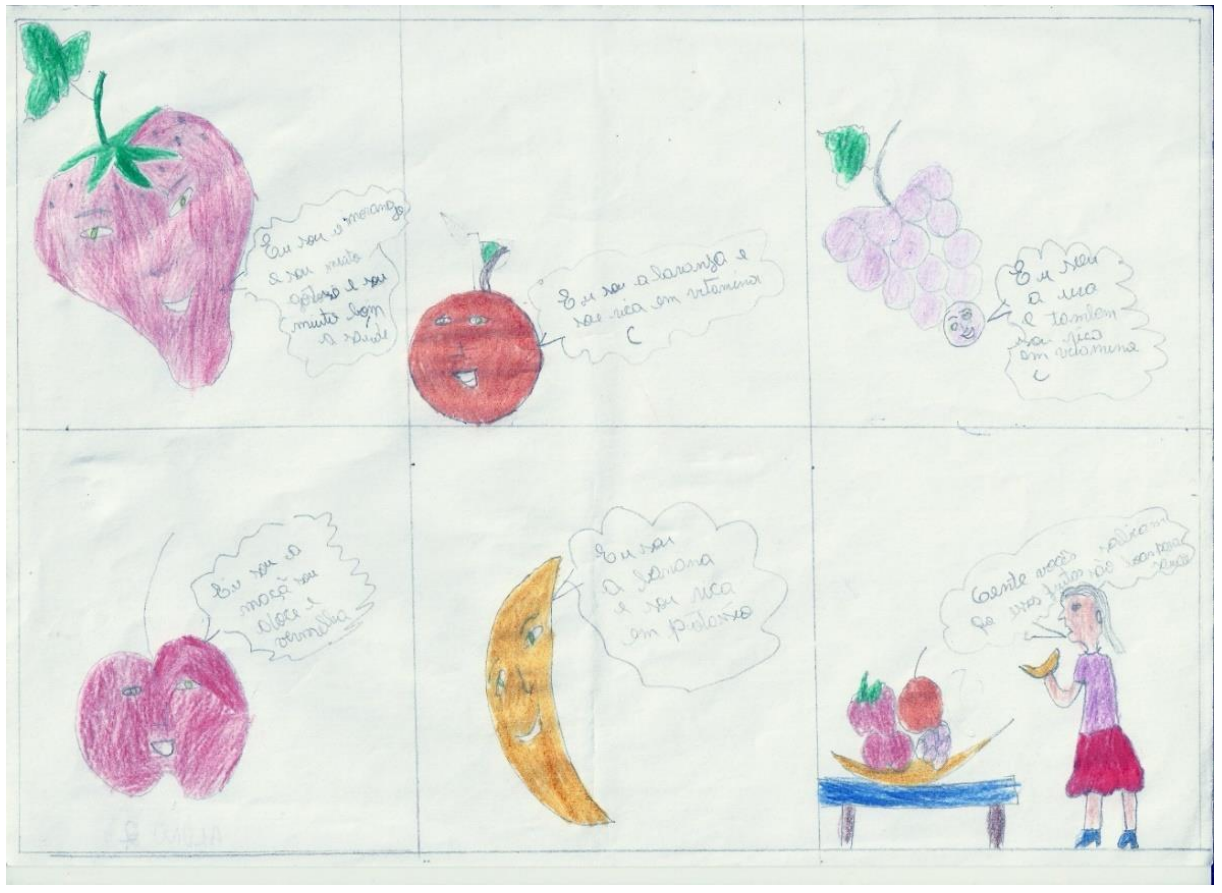

Fonte: elaborada pelos alunos desta amostragem. 
Figura 3: História em quadrinhos produzida pelo aluno 3

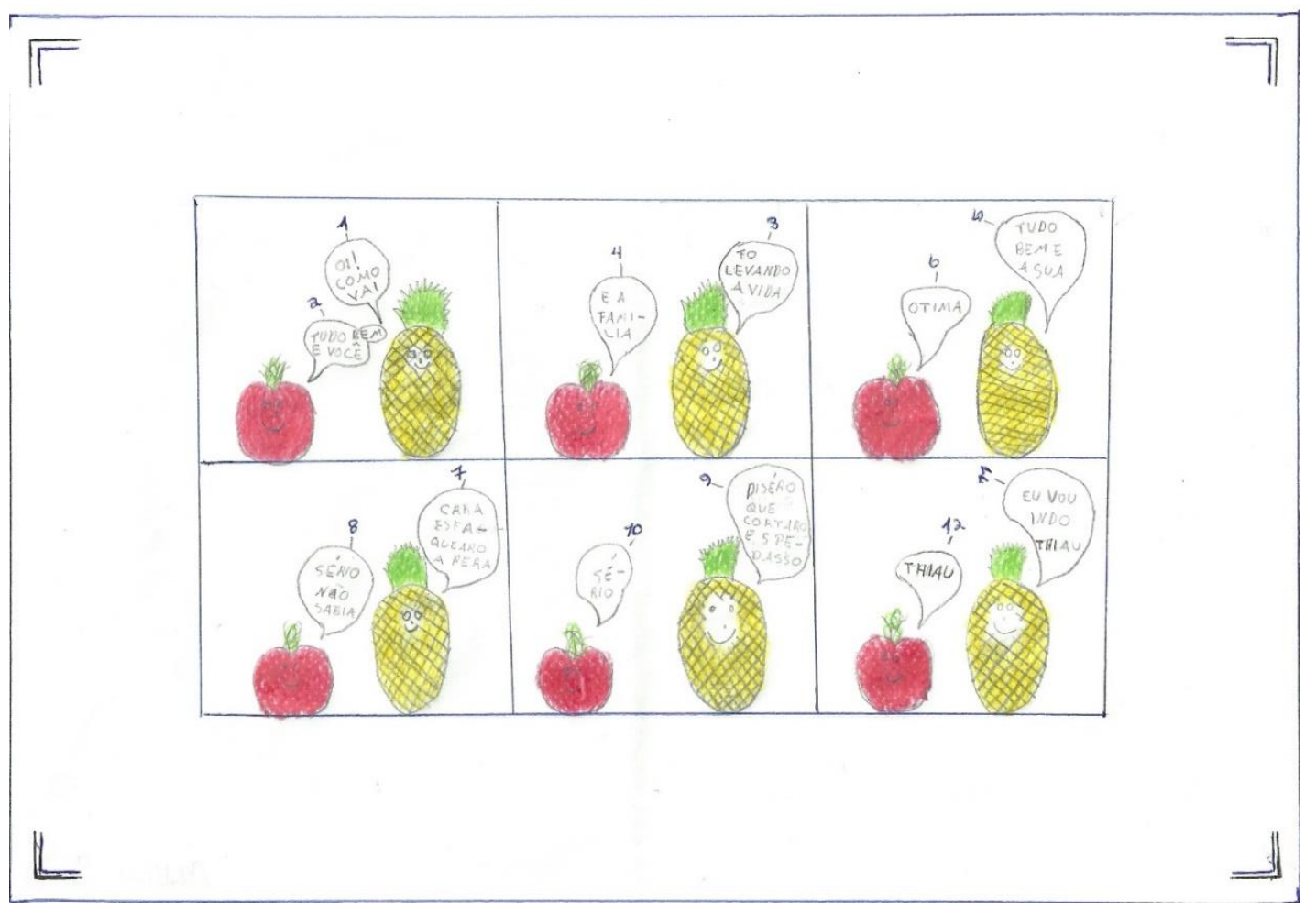

Fonte: elaborada pelos alunos desta amostragem.

Figura 4: História em quadrinhos produzida pelo aluno 4

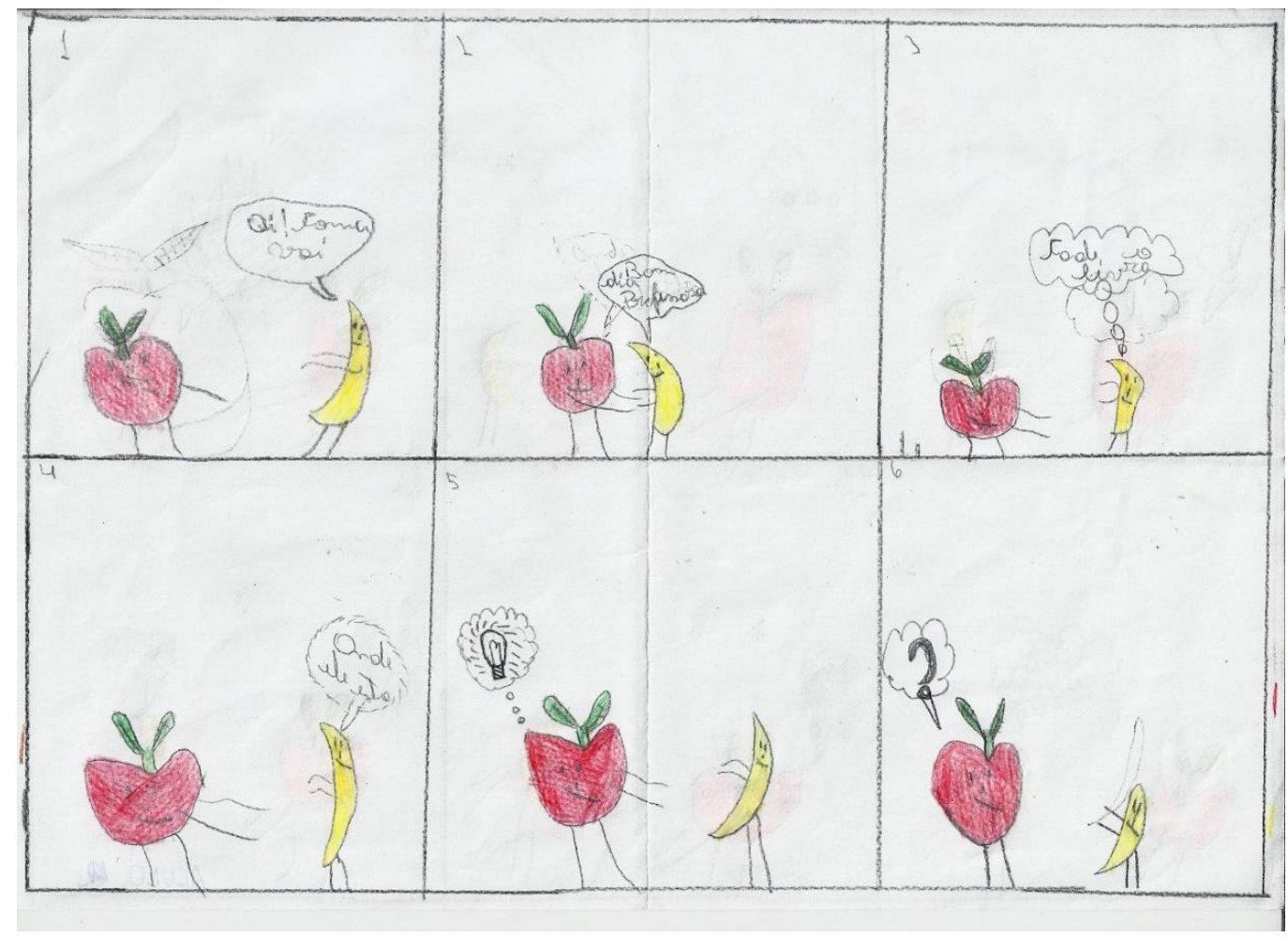

Fonte: elaborada pelos alunos desta amostragem. 
Figura 5: Segunda parte da história em quadrinhos produzida pelo aluno 4

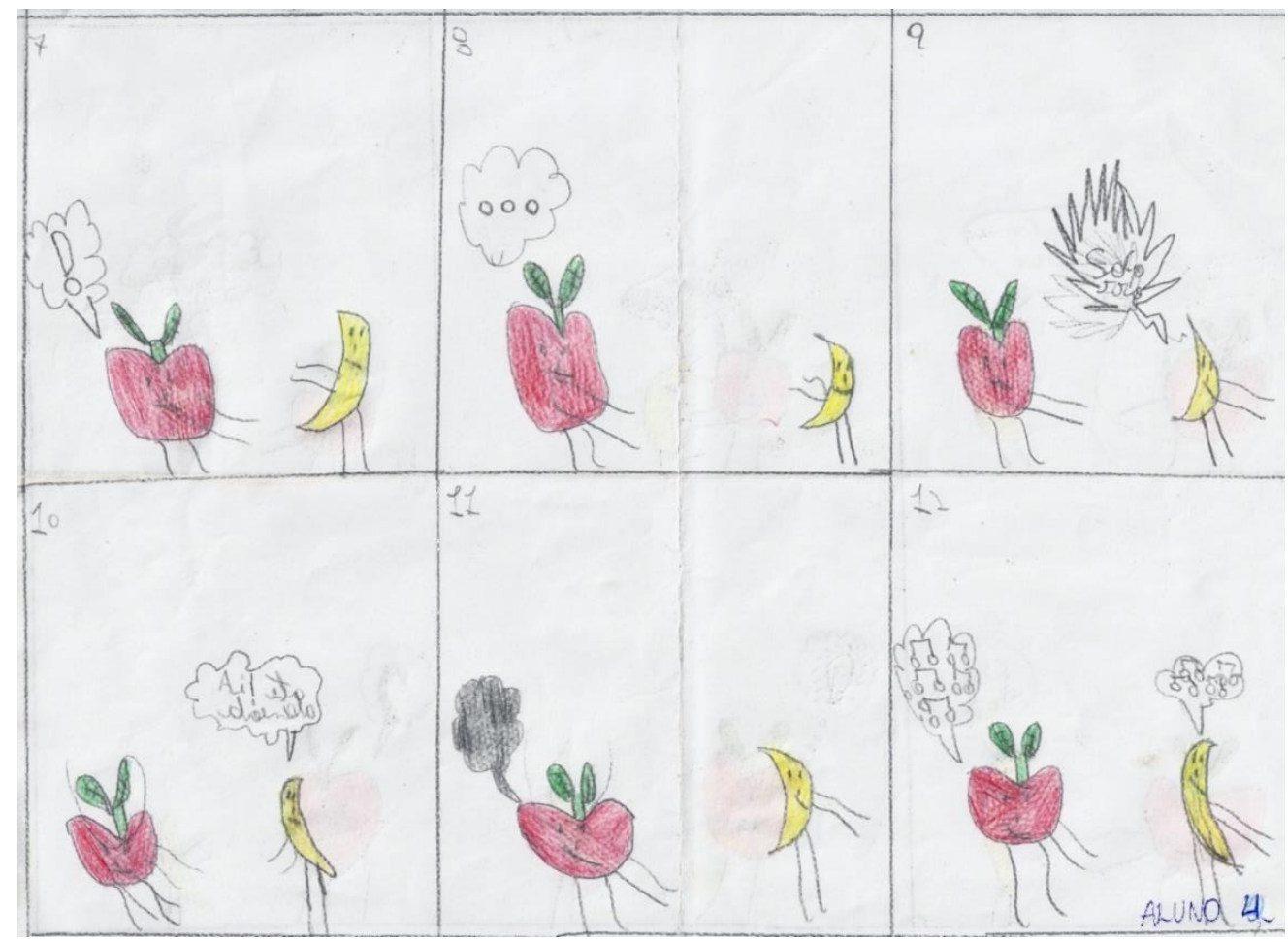

Fonte: elaborada pelos alunos desta amostragem

\section{Sequência lógico temporal}

Analisando a existência da sequência lógica temporal nos trabalhos sobre histórias em quadrinhos, os alunos 1 e 3 desenvolveram de forma clara, criando uma ordem de fatos, conforme o enredo da história. Já o aluno 4 se deteve mais ao uso de balões e movimentos gestuais dos personagens, deixando de lado a narrativa de uma história, conforme havíamos proposto.

"Criar a hipótese de continuidade e sequência da história, possibilita a percepção de sucessão temporal" (RAMOS, 2009, p. 131), permitindo o acompanhamento e desenvolvimento do aluno ao elaborar a tarefa de criar uma história. Os próprios alunos percebem, com clareza, a sequência da história produzida pelos colegas. Trata-se de uma característica da história em quadrinhos que pode ser trabalhada paralelamente à produção de redações, como a transformação de uma redação em história em quadrinhos, possibilitando assim que o próprio aluno perceba a necessidade de aprimorar a sequência dos fatos. 


\section{Estrutura do desenho}

Tratando-se da estrutura do desenho, o aluno 3, além de desenhar os personagens em ordem de acontecimentos, também identificou com números a ordem de cada balão. A HQ pode ser longa ou curta, mas todas têm um enredo com princípio meio e fim. O desenho e o texto são complementares, ou seja, um não faz sentido sem o outro. Já o aluno 2 fez a ilustração dos personagens de forma dispersa no espaço. Os alunos 1 e 4 produziram todos os desenhos com movimentos, expressando suas características através dos sentimentos gestuais. $\mathrm{O}$ desenho fez com que a leitura se tornasse mais rápida, identificando imediatamente a situação, um personagem ou uma cena.

Neste sentido Araújo, Costa e Costa (2008,), apresentam a ideia de que:

[...] a mensagem das histórias em quadrinhos é transmitida ao leitor por dois processos: por meio da linguagem verbal - expressa a fala, o pensamento dos personagens, a voz do narrador e o som envolvido - e por meio da linguagem visual - no qual o leitor interpretará as imagens contidas nas histórias em quadrinhos. Unindo estes dois processos, chega-se ao escopo que o enunciado verbal pretende transmitir ao leitor.

Para estes alunos, que apresentam dificuldades na leitura e escrita, a possibilidade de utilizar o desenho para expressar sua criação certamente facilitou a construção da história que tinha para contar aos colegas.

\section{Diálogo}

O diálogo entre os personagens foi desenvolvido nos trabalhos dos alunos 1 e 3 , onde estabeleceram a fala de dois personagens, contextualizando as ideias e a construção da história. Nos preocupamos com o fato do aluno ter a sua interpretação própria, compreendendo o que está lendo e iniciando a sua construção das falas.

A ligação entre o contexto da história, o desenho e o que os personagens dizem, promoveu a reflexão dos alunos nos diferentes momentos de trabalho. Este exercício constante, possibilitou o questionamento reconstrutivo da sua própria elaboração, acarretando maior autonomia no desempenho da tarefa. Este aspecto apresentou indícios dos benefícios de se trabalhar a história em quadrinhos, para tanto, o professor deve ter a competência de aproveitar toda a identidade cultural que o aluno apresenta para ajudá-lo na construção do seu conhecimento. A importância das histórias em quadrinhos nas escolas é tratada por Araújo, Costa e Costa (2008): 
[...] os quadrinhos podem ser utilizados na educação como instrumento para a prática educativa, porque neles podemos encontrar elementos composicionais que poderiam ser bastante úteis como meio de alfabetização e leitura saudável, sem falar na presença de técnicas artísticas como enquadramento, relação entre figura e fundo entre outras, que são importantes nas Artes Visuais e que poderiam se relacionar perfeitamente com a educação, induzindo os alunos que não sabem ler e escrever a aprenderem a ler e escrever a partir de imagens, ou seja, estariam se alfabetizando visualmente.

Nota-se a importância de desenvolver trabalhos que envolvam a interdisciplinaridade, pois eles favorecem uma articulação maior no processo de ensinoaprendizagem. Desenvolver meios em que os alunos possam aproveitar de maneira mais interativa, juntando vários campos de conhecimento. Trabalhar a escrita, a leitura, a pintura, o desenho, em só contexto, potencializa, de maneira natural, o desenvolvimento de habilidades e competências ligadas ao aprender a aprender.

No entanto, o aluno 4 não apresentou falas escritas, deixando de forma confusa a compreensão dos fatos. O aluno 2 não desenvolveu um diálogo entre os personagens, porém fez uma apresentação de cada personagem escolhido para a sua história. O diálogo é sempre muito usado, pois é o mais próximo à linguagem oral.

Somente o aluno 1 colocou o título na história em quadrinhos. A pintura dos desenhos foi muito valorizada.

Essas atividades demonstraram interesse e criatividade nos alunos envolvidos.

Valorizar o pensar do aluno e seus interesses, estabelecendo relações de troca onde o conhecimento seja compartilhado em um processo coletivo de aprender, faz com que se busque também desenvolver algumas competências e habilidades, criando espaços para que o aluno produza diversas possibilidades para ampliar seus conhecimentos.

\section{Considerações finais}

Desenvolver atividades através das histórias em quadrinhos desperta a imaginação e a criatividade, aguçando o interesse pela leitura e escrita. O gênero textual "História em Quadrinhos" vai além de cores e formas variadas de desenhos, busca explorar leituras, aprimorando a capacidade de análise, compreensão e reflexão do indivíduo. A construção dessa interação demonstra a importância de trabalhar com o "educar pela pesquisa", é importante que o aluno tenha a sua interpretação própria, compreendendo o que está lendo, propondo uma aprendizagem significativa e possibilitando ao aluno assumir o papel de 
autor, reconstruindo e elaborando seus materiais.

Através desse trabalho os alunos construíram de uma maneira mais dinâmica e envolvente a escrita e o gosto pela leitura. A união entre o desenho e a escrita torna essa leitura mais rápida e prazerosa. A interação com os colegas através de diálogos demonstrou enriquecimento no processo de ensino-aprendizagem e a formação de sujeitos críticos.

\section{REFERÊNCIAS}

ARAÚJO, G. C.; COSTA, M. A.; COSTA, E. B. As histórias em quadrinhos na educação: possibilidades de um recurso DidáticoPedagógico. Revista Eletrônica de Ciências Humanas, Letras e Artes, Uberlândia, n. 2, p. 26-27, jul./dez., 2008.

BARDIN, L. Análise de conteúdo. São Paulo: Edições 70, 2011.

DEMO, P. Educar pela pesquisa. 9 ed. Campinas/SP: Autores Associados, 2011.

GÓMEZ, A. M.; TÉRAN, N. Dificuldades de aprendizagem: detecção e estratégias de ajuda. Editora Grupo Cultural, 2008.

FARRELL, M. O aluno com necessidades Especiais na Escola Regular. Revista Pedagógica: Pátio , Porto alegre, a. XII, n. 48, p. 12-15, 2008/2009.

MELCHIOR, M. C. Da avaliação dos saberes à construção de competências. Novo Hamburgo/RS: Editora Premier, 2008.

PERRENOUD, Ph. Construir as competências desde a escola. Porto Alegre/RS:Artmed, 1999.

RAMOS, P. A leitura dos quadrinhos. São Paulo: Contexto, 2009.

SOLÉ, I. Estratégias de leitura. 6 ed. Porto Alegre: Artmed, 1998.

MANTOAN, M. T. A escola flexível e a pedagogia das diferenças. Revista Pedagógica: Pátio, Porto alegre, a. XII, n. 48, p. 16-18, 2008/2009.

VERGUEIRO, W. Uso das HQ no ensino. In: VERGUEIRO, W (Org). Como usar as histórias em quadrinhos na sala de aula. São Paulo: Contexto, 2004.

\section{Como referenciar este artigo}

KRÜGER, Camila Holz.; MICHELS, Josué. Colaboração do gênero textual história em quadrinhos no desenvolvimento da leitura e escrita. Doxa: Rev. Bras. Psico. e Educ., Araraquara, v. 20, n. 1, p. 20-31, jan./jun., 2018. e-ISSN: 2594-8385. DOI: 10.30715/rbpe.v20.n1.2018.10886 